\title{
Research on the Integration of Tsou Culture into Creative Board Game Design-an Example of Walk Around Laiji
}

\author{
Hsiu Ching Laura Hsieh ${ }^{1}$, Yu Hsien $\mathrm{Hsu}^{2}$ \\ ${ }^{1,2}$ Department and Graduate School of Creative Design, National Yunlin University of Science and Technology \\ "Corresponding author Email: jack11290115@gamil.com
}

\begin{abstract}
Aboriginal culture in Taiwan presents close interaction with societies in the time change that the living culture is seriously lost and gradually forgot. Tsou Laiji tribe, being surrounded by Han tribes, shows serious sinicization to result in the loss of local culture which is not acquainted by more people and inherited. The board game design - walk around Laiji extracts cultural codes from Tsou culture and integrates the cultural characteristics of Tsou Laiji tribe into board game design to perceive and understand the beauty of Tsou culture through the game experience. This study explains the process of extracting Tsou cultural elements and integrating into board game design by analyzing the design case of "walk around Laiji". The research objectives contain

1. To explain the extraction of Tsou cultural elements as well as the integration and application to board game design.
\end{abstract}

2. To discuss user experience in the application of Tsou culture to board game design.

Keywords: board game design, Tsou culture, cultural code

\section{INTRODUCTION}

\section{Background information}

Wang (2001) said that when faced with strong outside force and changes in social life, the impact on the Tsou people by the outside force will be reduced if the same cultural value and social structure principle remain unchanged. In recent years, with the development of diverse cultures in addition to reviving the culture and the language of the Tsou people, the establishment of museum is a consolidating force for each aborigine tribe. However for the Laiji tribe of the Tsou people, what they are facing is the lack of manpower to participate in the renaissance, plus the Tsou children cannot understand their own culture in depth, making the passing down of the culture a problem.

\section{LITERATURE REVIEW}

\section{2-1 The current state and historical evolu-} tion of that culture of the Tsou people.

The Tsous are dispersed in two areas. The Alishan (Ali Mountain) Tsous who live in and around the Alishan are called the 'Northern Tsous,' while the 'Southern Tsous' are the Saalua tribe in Taoyuan Village, Kanakannbu in Sanmin Village in Kaohsiung County. Currently, the main areas for the Tsou are the Alishan mountain area, Zengwen Dam, and the upstream of Zhuoshuei River. The population is about 6,000. The composition of the Tsou tribes consist of a big tribe that includes several small tribes and there are social positions of chief, elders, warriors, tribal member...The tribal members who became the embodiment of the whole tribe further bring rich his-
After interviewing local Laiji tribal members of the Tsou people, they wished to have the children and the youth understand the beauty of their culture through games or activities and take over the responsibility of passing down their culture. The research designed a table game"walk around Laiji", which extracts cultural icons and characteristics from the Laiji tribe so that the users will experience, feel, and understand the beauty of the Tsou culture.

\section{Research purpose}

There are two objectives to the research:

1. How to extract Tsou cultural elements into designing the table game.

2. Explore the user experience of applying Tsou culture into the game.

torical cultural background including economics, life, rituals, crafts... However, with the drastic changes in the entire social structure, the Tsou culture has been gradually dismantling under the influence of diverse culture. Their life has become more like the Han people. Tang(2002) also pointed out that the younger generation is unfamiliar with their own traditional culture and even lacks identity, with the emergence of many problems of the aborigine society. The disappearing of their mother tongue, traditional handcraft, ritual songs and dance are very alarming in that the culture of the Tsao people is facing the difficulty of development and passing on the legacy. Under the impact of modern civilization, there needs to be more wisdom and actions in order to earn more respect and 
understanding, more caring and space for developing the Tsou cultural characteristics.

\section{2-1-1 The Geographic Environment and Sight of the Tsous}

The sights at the environment where the Laiji tribes are located are (Aboriginal Digital Museum,2016) :

(1) Tianshuei Waterfall: the waterfall is about 150 200 meters falling from the top of Tashan all the way to the Laiji tribe. The nearby Tsou Legend Sightseeing Pagoda is the creation of the local wood sculpture masters with originality and fun.

(2) The Big Tashan and Small Tashan: the Tashans near Laiji is the sacred mountain for the Tsous where their god lives. The Tsous believe that the origin of life for the Tsous is Yushan and Tashan is where the spirit goes after death. The good ones will go to the Big Tashan, whereas the bad people's spirit would go to Small Tashan.

\section{2-2 Tabletop Game Features}

The table game is one that requires using your brain and hands, because the learning process involves integrated thinking and application of the thought (Treher,2011). Gobet, Voogt, Retschitzki (2004) proposed that all games must have an objective. So table game is not just a medium for establishing personal relationships, but it also has to achieve a certain goal. The designer must let the players gain experience from the table game which, after adjustment, will reach the most ideal condition in order to convey the content and function the game.

\section{2-3 User Experience}

The design concept for user experience is centered on the user, UX has been used in various professional areas, including product design and development, human-machine interface improvement (Hsu,2019). "Goal of the user experience" means the emotional characteristics while using the system. Preece, Rogers, Sharp (2007) proposed that the targets include satisfying, enjoyable, fun, entertaining, helpful, motivating, aesthetically pleasing, and supportive creativity. Therefore, the research developed the dimension of user experience according to Preece, Rogers, Sharp (2007), as listed in the following:

Table 1. The content of the four dimensions of the research

\begin{tabular}{ll}
\hline User experience target & $\begin{array}{l}\text { The research part of evaluation that for user } \\
\text { experience. }\end{array}$ \\
\hline satisfying, enjoyable, fun, entertaining & Game satisfaction dimension \\
\hline helpful, supportive creativity & Learning dimension of the game \\
\hline motivating & Functional dimension of the game \\
\hline aesthetically pleasing & Aesthetics dimension of the game \\
\hline
\end{tabular}

\section{RESEARCH METHOD}

The research deployed surveys and interviews to explore if a table game with Tsou cultural elements would let the users gain a deeper understanding of the Tsou culture. The research also developed a dimension survey based on the user's experience targets proposed by Preece, Rogers, Sharp (2007) and recorded the response and feedback of the user experience of evaluation. The in-depth interviews would allow the researchers to gain the recommendations from the users to improve on the game, increase the willingness to play in the users, and make the cultural elements of the game more complete.

\section{3-1 Subjects}

The objective of the research is to gain the user experience of the table game designed for Tsou culture. Therefore, there is a need to test the users for operating and understanding of the game. The subjects chosen were 10 Laiji tribe children between the ages of 7 and 12 .

Table 2. Coding for the interviewee

\begin{tabular}{ll}
\hline Interviewee & Identity coding \\
\hline Children of the Tsou Laiji tribe & $\mathrm{C}(\mathrm{C} 1 \cdot \mathrm{C} 2 \ldots \ldots$ and so on $)$ \\
\hline
\end{tabular}

\section{3-2 Research Design}

The table game of the research, "walk around Laiji", is a collection game with the main theme of getting to know Tsou culture and the animals and plants unique to Laiji based on the concept of the game 'Monopoly' in which the 'buying' concept was changed to that of 'collecting'. The overall intention is to present the Laiji culture in an approachable and vivid game. Hand drawn illustrations, detailed description will 
make it easy to understand by people of all ages. The exquisite 3-D props and cards bring out a different Laiji. The users need to 'collect' a designated card in
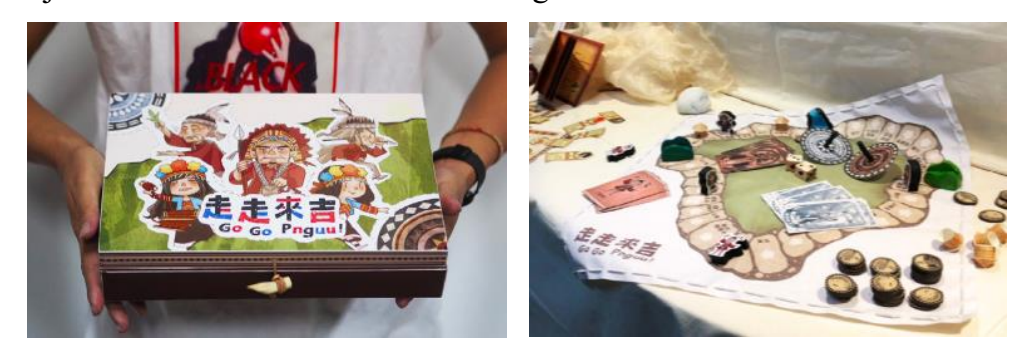

order to win while learning the Tsou culture and animals and plants unique to Laiji.

Figure 1. "walk around Laiji”table game (created by team members, Guo Zhi Wei, Kobayashi Chieko, Shu Yue

Table 3. "walk around Laiji" table game

Chen)

\begin{tabular}{|c|c|c|c|c|}
\hline Project & Design & Game Description & $\begin{array}{l}\text { Extraction } \\
\text { of elements }\end{array}$ & Cultural Codes \\
\hline \multirow{5}{*}{$\begin{array}{l}\text { Role } \\
\text { design }\end{array}$} & & Name of Character : Elder & & $\begin{array}{l}\text { In the form and dress } \\
\text { code of Tsou's elder }\end{array}$ \\
\hline & & Name of Character : Warrior & & $\begin{array}{l}\text { In the form and dress } \\
\text { code of Tsou's warrior }\end{array}$ \\
\hline & & $\begin{array}{l}\text { Name of Character } \\
\text { Wizard }\end{array}$ & & $\begin{array}{l}\text { In the form and dress } \\
\text { code of Tsou's wizard }\end{array}$ \\
\hline & & Name of Character : Lady & & $\begin{array}{l}\text { In the form and dress } \\
\text { code of Tsou's lady }\end{array}$ \\
\hline & & Name of Character : Young girl & & $\begin{array}{l}\text { In the form and dress } \\
\text { code of Tsou's young } \\
\text { girl }\end{array}$ \\
\hline $\begin{array}{l}\text { Card } \\
\text { design }\end{array}$ & 16. & $\begin{array}{l}\text { The players pick out the collection } \\
\text { cards and try to collect the } \\
\text { plant/animals on the cards. }\end{array}$ & & $\begin{array}{l}\text { Based on the draw- } \\
\text { ings in the 'Tsou Laiji } \\
\text { Legend' and 'Living } \\
\text { in Laiji' }\end{array}$ \\
\hline $\begin{array}{l}\text { Map } \\
\text { design }\end{array}$ & ${ }^{2}$ & $\begin{array}{l}\text { The surrounding sights, fauna and } \\
\text { flora are presented during the game } \\
\text { by throwing dice with combination } \\
\text { of legend and 'life card' }\end{array}$ & & $\begin{array}{l}\text { Improve visual design } \\
\text { based on the game } \\
\text { 'Monopoly' }\end{array}$ \\
\hline $\begin{array}{l}\text { Packaging } \\
\text { design }\end{array}$ & 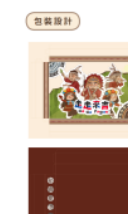 & $\begin{array}{l}\text { Easy storage after playing; coupled } \\
\text { with visual design that brings you } \\
\text { around Laiji to understand Tsou } \\
\text { culture, special plants and legend } \\
\text { stories. } 32 \times 22 \times 4.2(\mathrm{~cm})\end{array}$ & & $\begin{array}{l}\text { Element design based } \\
\text { on the colors in Lai- } \\
\text { ji's local surroundings }\end{array}$ \\
\hline
\end{tabular}




\begin{tabular}{|c|c|c|c|}
\hline 3-D object(1) & 000 & $\begin{array}{l}\text { At the beginning, the players are } \\
\text { distributed assets, for example : } 1 \\
\text { millet } \times 2,10 \text { millet } \times 2,50 \\
\text { millet } x 1 \text {. }\end{array}$ & $\begin{array}{l}\text { The millet in the Mil- } \\
\text { let Sacrifice Ritual as } \\
\text { element }\end{array}$ \\
\hline 3 -D object(2) & Sicis & $\begin{array}{l}\text { Tianshuei Waterfall, Big Tashan, } \\
\text { Small Tashan, and barns to let play- } \\
\text { ers experience the sights while play- } \\
\text { ing }\end{array}$ & $\begin{array}{l}\text { Using the } 3 \text { major } \\
\text { local sights and barns } \\
\text { as elements }\end{array}$ \\
\hline
\end{tabular}

\section{3-3 Research Method}

(1) First phase, having Laiji tribal members of the Tsou people as research subjects.

(2) Second phase, actual investigation and exploration of literature for analysis; going to the Laiji tribe to gain a deeper understanding of the local culture and life style and auxiliary verification by and with the literatures for the design elements.

(3) Third phase, applying the above analyzed and integrated element, the Tsou cultural icons were extracted for setting game rules and elements.

(4) Fourth phase, transform the cultural icons into the table game's design and creation, after finishing which, the beauty of the Tsou culture is con- veyed to each user.

(5) Fifth phase, explore the user experience and the dimensions of the survey was created based on the user experience targets as proposed by Preece, Rogers, Sharp. The research executed the survey and in-depth interviews for analysis.

There are 13 questions in the user experience dimension of survey according to the user experience targets as proposed by Preece, Rogers, Sharp (2007) and scores were given based on the Likert Scale. 10 Laiji tribal children filled out the survey after playing the game. The questions are as in Table 4 :

Table 4. The survey that is part of evaluation for the user experience of the research.

\begin{tabular}{|c|c|c|}
\hline Project & Question coding & Question \\
\hline \multirow{4}{*}{$\begin{array}{l}\text { Game satisfaction } \\
\text { dimension }\end{array}$} & Q1 & Is the game fun? \\
\hline & Q2 & Would you want to buy this game? \\
\hline & Q3 & Would you invite your friends to play the game together? \\
\hline & Q4 & Is this game a game you want to play? \\
\hline \multirow{2}{*}{$\begin{array}{l}\text { Learning } \\
\text { dimension of the } \\
\text { game }\end{array}$} & Q5 & Have you learned anything after playing the game? \\
\hline & Q6 & Is the game challenging to you? \\
\hline \multirow{6}{*}{$\begin{array}{l}\text { Functional } \\
\text { dimension of the } \\
\text { game }\end{array}$} & Q7 & Does the game suit your personal habit? \\
\hline & Q8 & Do you like the content of the game or how it's played? \\
\hline & Q9 & Is the game easy to play? \\
\hline & Q10 & Are the rules of the game more special than that of other games? \\
\hline & Q11 & Does the game need more functions? \\
\hline & Q12 & Are the rules of the game more special than that of other games? \\
\hline $\begin{array}{l}\text { Aesthetics } \\
\text { dimension of the } \\
\text { game }\end{array}$ & Q13 & Is the overall look beautiful? \\
\hline
\end{tabular}


Table 5. The statistical result of the survey of the research

(Scoring: 5 points for strongly agree, 4 for agree, 3 for no preference, 2 for disagree, and 1 point for strongly disagree)

\begin{tabular}{|c|c|c|c|c|c|c|c|c|c|c|c|c|}
\hline \multirow{2}{*}{ Project } & \multirow{2}{*}{$\begin{array}{l}\text { Question } \\
\text { coding }\end{array}$} & \multicolumn{10}{|c|}{ Factor } & \multirow{2}{*}{$\begin{array}{l}\text { Resulting } \\
\text { Score }\end{array}$} \\
\hline & & $\mathrm{C} 1$ & $\mathrm{C} 2$ & C3 & $\mathrm{C} 4$ & C5 & C6 & C7 & $\mathrm{C} 8$ & C9 & $\mathrm{C} 10$ & \\
\hline \multirow{4}{*}{$\begin{array}{l}\text { Game Satisfaction } \\
\text { Dimension }\end{array}$} & Q1 & 4 & 5 & 5 & 5 & 5 & 4 & 4 & 5 & 5 & 3 & 4.5 \\
\hline & Q2 & 5 & 5 & 4 & 5 & 5 & 4 & 4 & 4 & 4 & 4 & 4.4 \\
\hline & Q3 & 4 & 5 & 4 & 5 & 5 & 4 & 5 & 5 & 5 & 3 & 4.5 \\
\hline & Q4 & 5 & 5 & 5 & 5 & 5 & 3 & 4 & 4 & 4 & 4 & 4.4 \\
\hline \multirow{2}{*}{$\begin{array}{l}\text { Learning dimension of } \\
\text { the game }\end{array}$} & Q5 & 5 & 4 & 4 & 3 & 3 & 4 & 5 & 5 & 5 & 4 & 4.1 \\
\hline & Q6 & 5 & 5 & 4 & 5 & 5 & 3 & 3 & 4 & 4 & 3 & 4.1 \\
\hline \multirow{6}{*}{$\begin{array}{l}\text { Functional dimension } \\
\text { of the game }\end{array}$} & Q7 & 5 & 5 & 5 & 3 & 3 & 4 & 4 & 4 & 3 & 4 & 4.0 \\
\hline & Q8 & 5 & 5 & 5 & 4 & 5 & 4 & 5 & 4 & 4 & 4 & 4.5 \\
\hline & Q9 & 5 & 5 & 5 & 5 & 5 & 3 & 4 & 4 & 4 & 4 & 4.4 \\
\hline & Q10 & 4 & 5 & 4 & 4 & 5 & 4 & 5 & 4 & 3 & 3 & 4.1 \\
\hline & Q11 & 5 & 5 & 2 & 5 & 3 & 3 & 2 & 3 & 4 & 2 & 3.4 \\
\hline & Q12 & 4 & 5 & 4 & 4 & 5 & 4 & 5 & 4 & 3 & 3 & 4.1 \\
\hline $\begin{array}{l}\text { Aesthetics dimension } \\
\text { of the game }\end{array}$ & Q13 & 5 & 5 & 4 & 5 & 5 & 4 & 5 & 5 & 4 & 4 & 4.6 \\
\hline
\end{tabular}

The research conducted in-depth interviews of the 10 children after answering the survey questions. There are 4 que tions to the interview as in Table 6 :

Table 6. Interview questions of the research

\begin{tabular}{ll}
\hline Question coding & Interview question \\
\hline Q1 & Which part of the exterior do you feel needs improvement? (box, color, material) \\
\hline Q2 & What have you come to know or learned after playing the game? \\
\hline Q3 & What part of the game is the most special to you after playing the game? \\
\hline Q4 & Which part of the game do you feel needs improvement? (the map, cards, character) \\
\hline
\end{tabular}

(6) Sixth phase, the principle of design derived from the analysis of the research result to be provided to designers and developers in the future as reference.

\section{RESULTS}

The research explored the usability of a creative table game that is infused with Tsou tribal culture by adopting the dimension of user's experience of survey. There were a total of 10 Laiji children of the Tsou tribe who filled out the survey after the testing. The following are the results:

(1) In terms of game satisfaction dimension, the average scores for $\mathrm{Q} 1 \sim \mathrm{Q} 4$ are all above 4 points, indicating that the users were satisfied with the overall experience.
(2) In terms of learning dimension of the game, the average scores for Q5、Q6 are both above 4 points, indicating that the users could effectively understand the beauty of the Laiji culture, including (animals and plants, geography, cultural rituals... etc.).

(3) In terms of functional dimension of the game, the average scores for Q7、Q8、Q9、Q10、 Q12 are all above 4 points, indicating that the users felt that the functionality and usability of the game is very good from their game experi- 
ence.

(4) In terms of aesthetics dimension of the game, the average score for Q13 is above 4 points, indicating that the users felt the overall aesthetics of the game design as very beautiful.

After filling out the survey, the research conducted interview with questions as in Table 6 and arrived at the following result.

During the interview, the users were satisfied with the packaging and the colors of the game which is also easy to be transported and behooves Laiji's geography. The following interviews are such proof. 。

Subjects C6 and C10 responded :

"The colors befits Laiji's weather and are very different from other regular table games in the market." (C6 - Q1)

"The packaging is small and exquisite. The colors are nicely coordinated. It's easy to access." (C10-Q1)

During the interview, the users thought that they could gain better understanding of the Laiji culture from the game (animals and plants, geography, cultural rituals... etc.). The following interviews are such proof.。 Subjects C6、C7、C8 responded :

"I can gain better understanding of the Laiji culture and different cultural backgrounds through playing games." (C6-Q2)

"I have learned about the people, things, objects, especially the plants of the Laiji tribe of the Tsou people." (C7-Q2)

"There are giant elephant's ear, boars and other special plants and animals in the game from which I can learn about Laiji culture."(C8-Q2)

During the interview, the users thought that it is very special to put Tsou culture into the table game and that the content design is very good. The following interviews are such proof. Subjects C6、C7、C8、 C10 responded :

"Especially during the game, everybody had fun and was into character." (C6-Q3)

"The most special is the design of the coin based on the millet in the Millet Ritual, very good." (C7-Q3)

"The game has the Tsou's Laiji at its core; the content design is great." (C8-Q3)

"The characters are visually exquisite. The game rules are fun." (C10-Q3)

During the interview, the users thought that the game design is well-rounded and centers around Tsou's Laiji culture, very original. The following interviews are such proof.。 Subjects C9、C10 responded :

"The game was perfectly designed in that it has the originality of having Laiji culture in the game." (C9Q4)

"It already has the feel of a game. Well-rounded design and good texture." (C10-Q4)

\section{CONCLUSION}

From the result of the research, we arrived that the acceptance rate by the users in the table game "walk around Laiji" with Tsou cultural elements is high and that during the process of playing the game, better understanding of the beauty of the Tsou culture is achieved, with the addition of the Tsou people's grasp on their own and ecology is effectively enhanced. The research explores how to extract cultural icons in the creation process through the table game 'Let's Go Laiji', the problems and recommendations of the users during the research process. Four design principles were collated that can offer future designers and related game designers and developers as reference :

(1) Help creative table game design related areas by imbuing aboriginal culture into the game to develop user experience research.

(2) After experiencing the game, the users will be able to effectively learn the local fauna, flora, the people, geographic environment, cultural sacrifice ritual, and lifestyle, the beauty of Laiji culture.

(3) It is very special to the users to have Tsou culture elements imparted into the game which enhances willingness in users.

(4) The aesthetics of the table game design is based on extracting from local cultural icons in order to increase the satisfaction rate of the users in terms of game aesthetics.

\section{REFERENCES}

[1] Alishan National Scenic Area Administration (2018, Nov 21).Tsou Laiji[Online forum comment].Retrieved from https://www.alinsa.net/user/Article.aspx?La $\mathrm{ng}=1 \& \mathrm{SNo}=04003722$

[2] Aboriginal Digital Museum(2016, Jul.06).[Online forum comment].Tsou.Retrieved from http://www.dmtip.gov.tw/web/page/detail?11 $=2 \& 12=61 \& 13=28 \& 14=142$

[3] Bi Ma ,D .W.(2003) .Taiwan's aborigines : Tsou. Taiwan, Taipei : Taiyuan Publishing.

[4] Gobet, F., Voogt, A., Retschitzki, J. (2004). Moves in Mind: The Psychology of Board Games. Hove: Psychology Press.

[5] Hsu, C . C. (2019) . User experience research: An introduction , 36, 27-37.

[6] Preece,J., Rogers,Y.,Sharp,H.(2007).Interaction design:beyond human-computer . Chichester : Wiley

[7] Tang,H .C.(2002).Sustainable development of Tosu Taiwan's indigenous tribes

[8] The cases of Alishan Township Shanmei Community.National Chung Cheng University , Chiayi .

[9] Treher, E, N(2011)Learning with Board Games Tools for Learning and Retention Learning with Board Games Tools for Learning and Retention ,MN:The Learning Key. 